\title{
Efecto de la Suplementación del M edio de Maduración con Cisteamina y de Dos Medios de Cultivo (KSOM aa y SOF) en la Fecundación in vitro de Ovocitos Bovinos
}

\author{
Effect of Supplementation of Maturation Medium with Cysteamine and Two \\ Culture Media (KSOMaA and SOF) on in vitro Fertilization of Bovine Oocytes
}

Lisbeth Quintanilla M.1, Wilfredo Huanca L., ${ }^{1,3}$, Alejandro Córdova G. ${ }^{1}$, Antonio Ampuero B. ${ }^{2}$, Lenin Benavides $\mathrm{I}^{1}{ }^{1}$

\section{Resumen}

\begin{abstract}
Se evaluó el efecto de la cisteamina en el medio de maduración sobre la tasa de división posfecundación y el efecto de los medios de cultivo KSOMaa y SOF sobre la tasa de desarrollo embrionario in vitro hasta los 8 días posfecundación. Se utilizaron 680 ovocitos procedentes de ovarios de hembras bovinas distribuidos al azar en dos tratamientos: $\mathrm{T}_{1}(\mathrm{n}=321)$ medio de maduración TCM-199 y $\mathrm{T}_{2}(\mathrm{n}=359)$ medio de maduración TCM-199 adicionado con cisteamina $100 \mathrm{mM}$. Los ovocitos fueron fecundados a las $24 \mathrm{~h}$ con semen congelado de un solo toro y cultivados en medio KSOMaa por 18 h, evaluándose la tasa de división 72 h después. En la segunda fase, luego del primer cultivo, ambos grupos se subdividieron en dos grupos, donde el primero se cultivó con medio KSOMaa y el segundo con medio SOF hasta el día 8 posfecundación. Los resultados de la primera fase indican una tasa de división de $43.6 \%$ para el grupo control y $46.0 \%$ para el grupo suplementado con cisteamina, sin encontrar diferencia significativa. En la fase 2, se obtuvo una tasa de $18.0 \%$ de blastocistos para el tratamiento TCM-199 + KSOMaa y $20.9 \%$ para TCM-199 c/ cisteamina + KSOMaa (p<0.05), y 15.8\% para TCM-199 + KSOMaa y SOF y $18.7 \%$ para TCM-199 c/ cisteamina + KSOMaa y SOF ( $<<0.05)$. Los resultados indican que la adición de cisteamina al medio de cultivo mejoró la tasa de desarrollo embrionario in vitro hasta el estadio de blastocisto en ovocitos madurados en medio TCM 199, no habiendo diferencias por el uso de los medios de cultivo.
\end{abstract}

Palabras clave: fecundación in vitro, cisteamina, medio SOF, medio KSOM, bovino

\footnotetext{
${ }^{1}$ Laboratorio de Reproducción Animal, ${ }^{2}$ Laboratorio de Zootecnia y Producción Agropecuaria, Facultad de Medicina Veterinaria, Universidad Nacional Mayor de San Marcos, Lima, Perú

${ }^{3}$ E-mail: whuanca2002@yahoo.com
} 
The effect of the cysteamine in maturation medium on the oocyte cleavage rate and the effect of culture media KSOMaa and SOF on in vitro embryo development rate at 8 days post-fertilization was evaluated. A total of 680 oocytes from cattle ovaries were randomly distributed in two treatments: T1 $(n=321)$ maturation medium TCM-199 and T2 $(\mathrm{n}=359)$ maturation medium TCM-199 supplemented with $100 \mathrm{mM}$ cysteamine. Oocytes were fertilized after $24 \mathrm{~h}$ with frozen semen from a single bull and cultured in KSOMaa for $18 \mathrm{~h}$ and the fertilization rate was assessed $72 \mathrm{~h}$ after division. In the second phase, after the first culture, both groups were cultivated using two culture media: KSOMaa and SOF until day 8 post-fertilization. The results of the first phase showed a cleavage rate of $43.6 \%$ for the control group and $46.0 \%$ for the cysteamine supplemented group, without difference between groups. In phase 2, the blastocyst rate was $18.0 \%$ for the TCM-199+ KSOMaa and $20.9 \%$ for TCM-199 with cysteamine + KSOMaa ( $<<0.05)$, and $15.8 \%$ for TCM-199 + KSOMaa and SOF and $18.6 \%$ for TCM-199 with cysteamine + KSOMaa and $\mathrm{SOF}(\mathrm{p}<0.05)$. The results indicated that the addition of cysteamine to the culture media improved the in vitro embryo development rate to blastocyst in oocytes cultured in maturation medium TCM-199, and without differences due to the KSOMaa and SOF.

Key words: in vitro fertilization, cysteamine, SOF medium, KSOM medium, bovine

\section{INTRODUCCIÓN}

El éxito de la fecundación in vitro reside en la tasa de embriones lograda, de allí que se busca optimizar los factores que afectan su rendimiento, como pueden ser el efecto de las especies reactivas al oxígeno (ROS) producidas durante el metabolismo del ovocito y las condiciones del medio de cultivo en la etapa de división del zigoto y desarrollo a blastocisto (Correa et al., 2008).

Se ha podido determinar que la adición de cisteamina al medio de maduración de ovocitos bovinos incrementa los niveles de glutatión intracelular (Yoshida, 1993), el cual tiene entre sus funciones la protección de las células contra el daño oxidativo (Del Corso et al., 1994). Asimismo, la cisteamina se encuentra en el fluido del tracto reproductor de la hembra, por lo que debe tener un rol en el desarrollo embrionario (Gardiner et al., 1998).

Las condiciones de cultivo pueden interferir en el desarrollo normal del embrión, deteniendo la división embrionaria y bloquean- do el cuarto o quinto ciclo celular (Warzych et al., 2007) o alterando las membranas de los blastómeros (Pomar et al., 2005). Esta deficiencia está directamente relacionada con la competencia para el desarrollo de los embriones en estadio de blastocisto, por lo que se requiere continuar evaluando medios de cultivo que permitan incrementar la eficiencia en la obtención de blastocistos durante los procedimientos de cultivo de embriones bovinos.

El presente estudio, tuvo como objetivo evaluar el efecto de la suplementación del medio de maduración con cisteamina sobre la tasa de división post fecundación y evaluar dos medios de cultivo sobre el desarrollo embrionario in vitro de ovocitos bovinos.

\section{Materiales y Métodos}

Se colectaron ovarios de bovinos beneficiados en un centro de sacrificio local, ubicado en el distrito de Ate, Lima, Perú, entre los meses de junio a agosto de 2012. Los ova- 
rios fueron colectados en un termo conteniendo solución salina $(0.9 \%)$, suplementada con una solución de penicilina y estreptomicina en solución (Sigma P4333). La solución salina fue preparada con $9 \mathrm{~g}$ de cloruro de sodio (Sigma S5886) diluida en $1000 \mathrm{ml}$ de agua estéril y mantenida a una temperatura inicial de $37^{\circ} \mathrm{C}$ hasta el transporte al Laboratorio de Reproducción Animal de la Facultad de Medicina Veterinaria, Universidad Nacional Mayor de San Marcos, Lima.

En el laboratorio, los ovarios fueron lavados con solución salina. Luego se procedió a la colección de los complejos cúmuloovocitos (CCOs) fueron obtenidos mediante aspiración de folículos $\geq 7 \mathrm{~mm}$ (De Wit et al., 2000). Con la ayuda de un estereomicroscopio (400x), se procedió a la búsqueda y selección de ovocitos con citoplasma homogéneo finamente granulado y uniforme, el cual debe llenar el espacio delimitado por la zona pelúcida (Bertoldo et al., 2010). Los ovocitos recuperados fueron colocados en solución de lavado pre-maduración, compuesta de TL-Hepes (Sigma H4034) y suplementada con $6 \mathrm{mg} / \mathrm{ml}$ de polivinilpirrolidona (PVP) (Sigma P0930), $100 \mathrm{mM}$ de piruvato sódico (Sigma P5280), y luego fueron colocados en el medio de maduración compuesta de TCM199 (Sigma M2520), suplementada con 10\% suero fetal bovino (v/v), $100 \mathrm{mM}$ piruvato sódico, $5 \mathrm{mg} / \mathrm{m}$ gentamicina (Sigma G1264), $20 \mathrm{mg} / \mathrm{ml}$ de FSH (hormona folículo estimulante), $10 \mu \mathrm{g} / \mathrm{ml} \mathrm{hCG} \mathrm{y} 1 \mathrm{mg} / \mathrm{ml}$ de estradiol (Sigma E2758). Además, se adicionó $100 \mathrm{mM}$ de cisteamina al tratamiento 2. Los ovocitos fueron sometidos a maduración bajo condiciones de $39{ }^{\circ} \mathrm{C}, 5 \%$ de $\mathrm{CO}_{2}$ y humedad máxima, en gotas de $40 \mu \mathrm{l}$ cubiertas de aceite y colocadas en una placa petri.

Cumplidas las 24 horas de maduración, los ovocitos fueron retirados de las gotas de cultivo y colocados en el medio de fecundación, en gotas de $40 \mu \mathrm{l}$ cubiertas de aceite y colocadas en una placa petri bajo condiciones similares al proceso de maduración por espacio de $1 \mathrm{~h}$, para luego proceder a la fecundación con espermatozoides de bovino.

Para efectos de la fecundación, se utilizó semen procedente de un solo toro. La pajuela de semen fue descongelada en baño maría a $37{ }^{\circ} \mathrm{C}$ por $45 \mathrm{~s}$. Se colocó en una gradiente de Percoll (90/45), se centrifugó por $10 \mathrm{~min}$ a $600 \mathrm{~g}$, se retiró el sobrenadante, y se volvió a reconstituir con $5 \mathrm{ml}$ de TLHEPES (Sigma H4034). Se centrifugó nuevamente por $5 \mathrm{~min}$ a $300 \mathrm{~g}$, se decantó el sobrenadante y el pellet fue reconstituido con $30 \mu \mathrm{l}$ de TL-Stock.

Se colocó $2 \mu 1$ de la solución de espermatozoides, PHE (penicilamina [P4875], hipotaurina [H1384] y epinefrina [E1635]) y heparina $2 \%$ para lograr la fecundación de los ovocitos. Luego de 18 horas de co-cultivo de gametos, se colocaron los presuntos zigotos en viales de $2 \mathrm{ml}$ para retirar el cumulus. Con el apoyo del estereoscopio, los ovocitos desnudos fueron lavados, colocados en gotas de $580 \mu \mathrm{l}$ cubiertas de aceite mineral, que fueron preparadas e incubadas por un mínimo de $12 \mathrm{~h}$ a $39{ }^{\circ} \mathrm{C}$ y $5 \%$ de $\mathrm{CO}_{2}$ previo a la colocación de los presuntos zigotos.

Los presuntos zigotos fueron separados según el grupo de estudio correspondiente (con y sin cisteamina) y colocados en medio KSOMaa (potassium simplex optimization medium) por $72 \mathrm{~h}$ en una estufa bajo una mezcla de gases de $5 \%$ de oxígeno, $5 \%$ de $\mathrm{CO}_{2}$ y $90 \%$ de nitrógeno a $39^{\circ} \mathrm{C}$ y humedad relativa máxima. Luego, se evaluó la tasa de división posfecundación de cada grupo en base al número de zigotos y el total de ovocitos cultivados.

\section{Segundo Cultivo}

Se prepararon gotas de $40 \mu 1$ de medio SOF (synthetic oviductal fluid) cubiertas con aceite mineral para los grupos 2 y 4 , y de medio KSOMaa para los grupos 1 y 3 . En ambos casos, las gotas fueron pre-incubadas por al menos $12 \mathrm{~h}$ a $39{ }^{\circ} \mathrm{C}$ y $5 \%$ de $\mathrm{CO}_{2}$. 
Cumplidas las $72 \mathrm{~h}$, los zigotos fueron retirados, lavados y colocados en las gotas respectivas. Los medios de cultivo SOF y KSOMaa fueron renovados cada 72 horas, retirando el medio y colocando un nuevo medio en cada gota.

Los zigotos permanecieron hasta el día ocho posfecundación en estas gotas dentro de una cámara individual con una mezcla de gases de $5 \%$ de $\mathrm{O}_{2}, 5 \%$ de $\mathrm{CO}_{2}$ y $90 \%$ de nitrógeno a $39{ }^{\circ} \mathrm{C}$ y humedad relativa máxima.

\section{Desarrollo Embrionario}

Se evaluó cada gota de cada tratamiento a los ocho días de la fecundación para observar los blastocistos y determinar la tasa de desarrollo embrionario, en base a los blastocistos observados del total de ovocitos cultivados.

En síntesis, los ovocitos fueron distribuidos en los siguientes grupos:

G1 (n= 156): Maduración TCM 199 + Cultivo KSOMaa

G2 (n= 165): Maduración TCM 199 + Cultivo KOMaa + SOF

G3 (n=182): Maduración TCM $199+$ Cisteamina + Cultivo KSOMaa

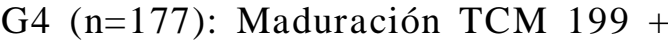
Cisteamina + Cultivo KSOMaa + SOF

\section{Análisis Estadístico}

Los resultados se evaluaron mediante comparación de proporciones con la prueba de Chi cuadrado.

\section{Resultados}

En el Cuadro 1 se muestra la tasa de división de los ovocitos madurados sin adición de cisteamina (G1 y G2) y con adición de cisteamina (G3 y G4) en el medio de ma- duración. No se encontró diferencia estadística entre tratamientos.

El Cuadro 2 muestra la tasa de blastocistos en el día ocho posfecundación luego de ser cultivados con o sin cisteamina en KSOMaa como único medio o con SOF. Las mejores tasas de fecundación se obtuvieron con la adición de cisteamina, independientemente del medio utilizado.

\section{Discusión}

La inclusión de cisteamina en el medio de maduración no tuvo un efecto biológico significativo en la tasa de división posfecundación (Cuadro 1), pero fue importante cuando la evaluación abarcó la tasa de desarrollo embrionario hasta el estadio de blastocisto (Cuadro 2, p<0.05).

Los resultados pueden explicarse si se considera que la fase de maduración de ovocitos bajo condiciones in vivo requiere un mayor periodo de tiempo que las 24 horas utilizadas bajo condiciones in vitro. Los eventos fisiológicos que se desarrollan a partir del proceso de selección folicular permiten que, en el caso de bovinos, solo uno continúe con su desarrollo hasta alcanzar el estadio de folículo dominante, mientras que el resto quedan relegados a la atresia folicular por un proceso de apoptosis. Así, en la maduración in vitro, si bien se dan ciertas condiciones (oxígeno, temperatura, $\mathrm{pH}$, gases, etc.) para que un mayor porcentaje alcance la metafase II, no se logra proporcionar todas las condiciones requeridas (Greenwood y Gautier, 2005) y llegan a ocurrir fallas en la cadena respiratoria (Cadenas y Davies, 2000) que favorecen la producción de altos niveles de ROS. Esto, sumado a la alteración en la dinámica de distribución y función mitocondrial, desencadena la apoptosis en distintas etapas del desarrollo y el bloqueo de embriones en el cuarto ciclo celular (Serrano y Olivera-Angel, 2003). 
Cuadro 1. Efecto de la adición de cisteamina en la tasa de división de ovocitos de bovino a las 72 horas posfecundacion

\begin{tabular}{lccc}
\hline \multirow{2}{*}{ Tratamiento } & \multirow{2}{*}{ Número de ovocitos } & \multicolumn{2}{c}{ Ovocitos divididos } \\
\cline { 3 - 4 } & & $(\mathrm{n})$ & $(\%)$ \\
\hline TCM-199 & 321 & 140 & 43.6 \\
TCM-199 + cisteamina & 359 & 165 & 46.0 \\
\hline
\end{tabular}

Cuadro 2. Efecto de la adición de cisteamina y del medio de cultivo sobre la tasa de blastocistos de bovino en el día ocho posfecundación

\begin{tabular}{lccc}
\hline \multirow{2}{*}{ Tratamiento } & Número de & \multicolumn{2}{c}{ Blastocistos } \\
\cline { 3 - 4 } & $\begin{array}{c}\text { ovocitos } \\
\text { cultivados }\end{array}$ & $(\mathrm{n})$ & $(\%)$ \\
\hline TCM-199 + KSOMaa & 156 & 28 & $18.0^{\mathrm{a}}$ \\
TCM-199 + KSOMaa y SOF & 165 & 26 & $15.8^{\mathrm{a}}$ \\
TCM-199 c/ cisteamina + KSOMaa & 182 & 38 & $20.9^{\mathrm{b}}$ \\
TCM-199 c/ cisteamina + KSOMaa y SOF & 177 & 33 & $18.6^{\mathrm{b}}$ \\
\hline
\end{tabular}

${ }^{a, b}$ Superíndices diferentes presentan diferencia estadística $(p<0.05)$

Diversos estudios sugieren que esta apoptosis se debería a la expresión de genes proapoptóticos como el NF8B (Takada et al., 2003) y p53 (Velez-Pardo et al., 2007); sin embargo, estos han sido encontrados en distintas etapas embrionarias y en embriones competentes. Por otro lado, se ha demostrado que el bloqueo de las caspasas resulta nocivo para el embrión, aunque no está claro el mecanismo de acción (Zakeri et al., 2005).

La tasa de división posfecundación no fue afectada por la adición de cisteamina. Esto podría deberse a que el medio empleado en la maduración, TCM 199, contiene una cantidad pequeña de glutatión (GSH) y de su precursor, la cisteína. La presencia de esta cantidad de GSH podría ser suficiente para proteger a los ovocitos del estrés oxidativo y la cisteína sería capaz de mantener un buen nivel de síntesis de GSH durante la maduración in vitro (Luvoni et al., 1996).

La inclusión de cisteamina en el medio de maduración permite almacenar altos niveles de GSH intracelular, permaneciendo estos a manera de reserva para la protección del embrión hasta el estadio de blastocisto (De Matos et al., 1996). Niveles elevados de GSH permanecen en los ovocitos tras la maduración hasta el estadio del embrión de ocho células, previo al bloqueo del desarrollo embrionario temprano y expresión del genoma, actuando como tampón metabólico eliminando los agentes oxidantes (Memili y First, 2000). En el presente estudio se comprobó que la adición de cisteamina en el medio de maduración incrementó la producción de blastocistos bovinos, como ya fuera demostrado por De Matos et al. (1996). 
En los estadios más tempranos (embriones de 1-2 células) se utiliza el piruvato o el lactato mas no la glucosa, ya que esta no es bien aprovechada por el embrión en esos estadios (Takahashi y First, 1992). El piruvato y el lactato son componentes importantes en el medio KSOMaa. Por otro lado, la glucosa es utilizada por el embrión a partir del estadio de ocho células hasta el estadio de blastocisto (Rieger et al., 1992), y esta sustancia se encuentra en mayor proporción en el medio SOF. No obstante, en el presente estudio no se halló diferencia estadística en la tasa de blastocisto entre los tratamientos de KSOMaa como único medio de cultivo y el tratamiento de KSOMaa para estadios tempranos y medio SOF hasta blastocisto, debido probablemente a que las cantidades de piruvato, glucosa y lactato fueron suficientes para el desarrollo del embrión.

Por último, en relación a los aminoácidos, aunque se encuentran en mayor proporción en el medio KSOMaa que en el medio SOF, es posible que a partir de la compactación del embrión, este presente un epitelio transportador y, por lo tanto, pueda regular su ambiente interno y el pH (Anbari y Schultz, 1993; Edwards et al., 1998). Esto sugiere que la concentración de aminoácidos no es determinante para su utilización en la etapa posterior a la compactación.

\section{Conclusiones}

La adición de cisteamina al medio de cultivo mejoró la tasa de desarrollo embrionario in vitro hasta el estadio de blastocisto en ovocitos bovinos madurados en medio TCM 199.

\section{Literatura Citada}

1. Anbari K, Schultz R. 1993. Effect of sodium and betaine in culture media on development and relative rates of protein synthesis in preimplantation mouse embryos in vitro. Mol Reprod Dev 35: 24-28. doi: $10.1002 / \mathrm{mrd} .1080350105$

2. Bertoldo M, Holvoake P, Evans G, Grupen C. 2010. Oocyte developmental competence is reduced in sows during the seasonal infertility period. Reprod Fert Dev 22: 122-1229. doi: 10.1071/RD10093

3. Cadenas E, Davies K. 2000. Mitochondrial free radical generation, oxidative stress, and aging. Free Radic Biol Med 29: 222-230. doi: 10.1016/ S0891-5849(00)00317-8

4. Correa GA, Rumpf R, Duarte TC, Franco MM, Nunes D, Alves M. 2008. Oxygen tension during in vitro culture of bovine embryos: effect in production and expression of genes related to oxidative stress. Anim Reprod Sci 104: 132-142. doi: 10.1016/j.anireprosci. 2007.02.002

5. De Matos D, Furnus C, Moses D, Matkovic M, Martinez AG. 1996. Stimulation of glutathione sínthesis of in vitro matured and its effect on embryo development and freezability. Mol Reprod Dev 45: 451-457.

6. Del Corso A, Capiello M, Mura U. 1994. Thiol dependent oxidation of enzymes: The last chance against oxidative stress. Int J Biochem 26: 745750. doi: 10.1016/0020-711X(94)90103-1

7. De Wit AAC, Wurth YA, Kruip ThAM, 2000. Effect of ovarian phase and follicle quality on morphology and developmental capacity of the bovine cumulus-oocyte complex. J Anim Sci 78: 1277-1283.

8. Edwards L, Williams D, Gardner D. 1998. Intracellular $\mathrm{pH}$ of the preimplantation mouse embryo: amino acids act as buffers of intracellular $\mathrm{pH}$. Hum Reprod 13: 3441-3448.

9. Gardiner C, Samen J, Brandt C, Stover S. 1998. Glutathione is present in reproductive tract secretion and improves development of mouse embryos after chemically induced glutathione depletion. Biol Reprod 59: 431-436. doi: 10.1095/ biolreprod59.2.431 
10. Greenwood J, Gautier J. 2005. From oogenesis through gastrulation: developmental regulation of apoptosis. Semin Cell Dev Biol 16: 215-224. doi: 10.1016/j.semcdb.2004.12.002

11. Luvoni G, Keskintepe L, Brackett B. 1996. Improvement in bovine embryo production in vitro by glutathionecontaining culture media. Mol Reprod Dev 43: 437-443.

12. Memili E, First N. 2000. Zygotic and embryonic gene expression in cow: A review of timing and mechanisms of early gene expression as compared with other species. Zygote 8: 87-96. doi: 10.1017/S0967199400000861

13. Pomar FJ, Teerds KJ, Kidson A, Colenbrander B, Tharasanit $T$, Aguilar B, Roelen BA. 2005. Differences in the incidence of apoptosis between in vivo and in vitro produced blastocysts of farm animal species: A comparative study. Theriogenology 63: 2254-2268.

14. Rieger D, Loskutoff N, Betteridge J. 1992. Developmentally related changes in the metabolism of glucose and glutamine by cattle embryos produced and co-cultured in vitro. J Reprod Fert 95: 585-595.

15. Serrano C, Olivera-Angel M. 2003. Detenimiento en el ciclo celular de embriones bovinos producidos in vitro. Taurus 5: 20-35.
16. Takada Y, Mukhopadhyay A, Kundu $G$, Mahabeleshwar G, Singh S, Aggarwal B. 2003. Hydrogen peroxide activates $\mathrm{NF} \kappa \mathrm{B}$ through tyrosine phosphorylation of $\operatorname{IkB} \alpha$ and serine phosphorylation of p65. J Biol Chem 278: 24233-24241.

17. Takahashi Y, First N. 1992. In vitro development of bovine one-cell embryos: influence of glucose, lactate, pyruvate, amino acids and vitamins. Theriogenology 37: 963-978.

18. Velez-Pardo C, Morales A, Del Rio M, Olivera-Angel M. 2007. Endogenously generated hydrogen peroxide induces apoptosis via mitochondrial damage independent of NF-kappaB and p53 activation in bovine embryos. Theriogenology 67: 1285-1296. doi: 10.1016/j.theriogenology.2007.01.018

19. Warzych E, Wrenzycki C, Peippo J, Lechniak D. 2007. Maturation medium supplements affect transcript level of apoptosis and cell survival related genes in bovine blastocysts produced in vitro. Mol Reprod Dev 74: 280-289.

20. Yoshida M. 1993. Role of glutathione in the maturation and fertilization of pig oocytes in vitro. Mol Reprod Dev 35: 76-81.

21. Zakeri Z, Lockshin R, CriadoRodríguez L, Martínez AC. 2005. A generalized caspase inhibitor disrupts early mammalian development. Int J Dev Biol 49: 43-47. 